\title{
Avaliação de híbridos de girassol e relação entre parâmetros produtivos e qualitativos ${ }^{1}$
}

\author{
Evaluation of sunflower hybrids and the relationship between productive and \\ qualitative parameters
}

\author{
Laerte Gustavo Pivetta ${ }^{2 *}$, Vandeir Francisco Guimarães ${ }^{3}$, Samuel Luiz Fioreze$^{2}$, Laércio Augusto Pivetta² e \\ Gustavo Castoldi²
}

\begin{abstract}
RESUMO - O presente estudo teve o objetivo de determinar genótipos superiores de girassol, bem como realizar estudos de correlação entre suas características. Avaliou-se seis híbridos de girassol em condições de safrinha no município de Palotina - PR. O estudo avaliou quinze variáveis: massa seca de folhas, massa seca de caule e pecíolos, massa seca total, área foliar, altura de planta, diâmetro de colmo, massa de grãos por capítulo, diâmetro de capítulo, percentagem de grãos normais, massa de mil grãos, número de grãos por capítulo, produtividade, teor de proteína bruta, teor de óleo e rendimento de óleo. Os dados direcionam os híbridos H360 e MG2 com boa produtividade e maior teor de óleo para a produção de óleo e os híbridos M734 e Aguará 3 para a alimentação animal, com boa produtividade e menor teor de óleo. As correlações entre produtividade e os componentes de produção foram de 0,$62 ; 0,47 ; 0,60 ; 0,49$ e 0,47 para massa de grãos por capítulo, diâmetro de capítulo, percentagem de grãos normais, massa de mil grãos e número de grãos por capítulo, respectivamente, concluindo que a seleção de materiais a partir desses componentes ocasionará a seleção de materiais promissores em produtividade.
\end{abstract}

Palavras- chave: Hellianthus annuus L. Correlação. Genótipos.

\begin{abstract}
The objective of this work was to determine superior genotypes of the sunflower, as well as to study the correlation between its characteristics. Six sunflower hybrids were evaluated under late-summer conditions in Palotina in the state of Paraná. The study evaluated fifteen variables: leaf dry mass, stem and petiole dry mass, total dry mass, leaf area, plant height, stem diameter, grain weight per head, head diameter, percentage of normal grains, thousand grain weight, number of grains per head, productivity, crude protein content, oil content and oil yield. According to the data, the hybrids H360 and MG2, with good productivity and higher oil content, are indicated for oil production, and the hybrids M734 and Aguará 3, with good productivity and lower oil content, for animal feed. The correlation between productivity and yield components were $0.62,0.47,0.60,0.49$ and 0.47 , for grain weight per head, head diameter, percentage of normal grains, thousand grain weight and number of grains per head respectively, leading to the conclusion that the selection of materials from among these components will result in the selection of promising materials for productivity.
\end{abstract}

Key words: Hellianthus annuus L. Correlation. Genotypes.

\footnotetext{
*Autor para correspondência

${ }^{1}$ Recebido para publicação em 14/10/2010; aprovado em 14/02/2012

Parte da Monografia do primeiro autor apresentada na Universidade Estadual do Oeste do Paraná - UNIOESTE, Campus de Marechal Cândido Rondon

${ }^{2}$ Programa de Pós-Graduação em Agricultura, Departamento de Produção Vegetal, Faculdade de Ciências Agronômicas/UNESP, Caixa Postal 237, Botucatu-SP, Brasil, 18.610-307, lgpivetta@fca.unesp.br, sl_fioreze@yahoo.com.br, laerciopivetta@yahoo.com.br, castoldi@fca.unesp.br ${ }^{3}$ Programa de Pós-Graduação em Agronomia, Centro de Ciências Agrárias, Universidade Estadual do Oeste do Paraná/UNIOESTE, Campus de Marechal Cândido Rondon, Rua Pernambuco, 1777, Caixa Postal 1008, Marechal Cândido Rondon-PR, Brasil, 85.960-000, vandeirfg@yahoo.com.br
} 


\section{INTRODUÇÃO}

Com uma estimativa de produção brasileira de grãos de 148.996,4 mil toneladas na safra 2009/2010, estima-se que o girassol contribua com apenas 80,6 mil toneladas (CONPANHIA NACIONAL DE ABASTECIMENTO, 2010), ou seja, apenas $0,054 \%$ de toda a produção nacional. A inserção do girassol no processo produtivo pode ser viabilizada pelo fato de que a sua cadeia produtiva utiliza, com algumas adaptações técnicas, a mesma estrutura produtiva disponível para a produção e o processamento da maior parte dos outros grãos. Além disso, devidoàoleaginosa poder ser semeada a partir de fevereiro após colheita da safra normal de verão, na "safrinha", há possibilidades para que tanto o produtor rural quanto o industrial, diminuam a ociosidade dos recursos produtivos, aumentem as receitas, tragam maior equilibro ecológico ao sistema produtivo (LAZZAROTTO; ROESSING; MELLO, 2005).

As características citadas acima se encaixam na região Oeste do Paraná, região esta com tradição na produção de grãos, que possui agricultura altamente mecanizada e tecnificada. Porém, nos últimos anos o cultivo em "safrinha" tornou-se muito arriscado devido aos problemas climáticos (secas e geadas), sendo que as culturas tradicionais como milho e trigo não apresentam resultado satisfatório. Segundo Castro e Farias et al. (2005) o girassol possui características favoráveis, possuindo maior tolerância à seca, ao frio e ao calor, quando comparado com a maioria das espécies cultivadas no Brasil. Dessa forma a cultura possui boas perspectivas de aumento do cultivo em regiões com adversidades climáticas.

Em escala mundial, a expansão e o estabelecimento da cultura do girassol como oleaginosa foram possíveis em função dodesenvolvimentodenovas cultivares, responsáveis por cerca de $60 \%$ dos avanços obtidos no rendimento (CASTIGLIONI; OLIVEIRA, 1999). E para que a cultura amplie essa expansão, os programas de melhoramento devem ser direcionados à obtenção de genótipos de girassol com alto rendimento de grãos, alto teor de óleo, ciclo precoce, porte reduzido, resistência às doenças, tolerância ao alumínio e à seca (OLIVEIRA et al., 2005). Além dessas características, Marcos Filho (2005) aponta como objetivo dos programas de melhoramento a obtenção de sementes de composição química específica, visando o atendimento de diferentes tipos de consumidores, ou seja, alimentação humana, animal ou indústria.

A escolha adequada da cultivar mais produtiva e mais adaptada às condições da região consiste em uma tecnologia essencial para obter incremento na produtividade, especialmente por ser uma prática que não onera substancialmente o custo de produção (PAES, 2005). Por isso, a avaliação contínua de genótipos é de grande importância a fim de determinar o comportamento agronômico dos mesmos e sua adaptação às diferentes condições locais (PORTO et al., 2007), sendo de grande importância os ensaios de avaliação de genótipos (HECKLER, 2002; IVANOFF et al., 2010).

Alguns ensaios em girassol têm como objetivo avaliar o potencial produtivo e estimar correlações entre diferentes características agronômicas em vários genótipos (CHIKKADEVAIAH et al., 2002; FARHATULLAH et al., 2006; HLADNI et al., 2006; HABIB et al., 2007; KAYA et al., 2007; KHAN 2001; MACHIKOWA; SAETANG, 2008; MIJIC et al., 2009).

O objetivo do presente estudo foi avaliar genótipos de girassol, determinando assim genótipos superiores, e estudar as relações existentes entre as características fenotípicas produtivas e qualitativas.

\section{MATERIAL E MÉTODOS}

$\mathrm{O}$ experimento foi conduzido no município de Palotina - PR, na Estação Experimental da C Vale Cooperativa Agroindustrial, localizada a 2420'32" de latitude Sul e 5351'36" de longitude Oeste, a uma média de $355 \mathrm{~m}$ de altitude. A semeadura foi realizada no dia 28 de fevereiro de 2007. A adubação no plantio foi de $415 \mathrm{~kg} \mathrm{ha}^{-1}$ da formulação 2-20-18, com $5 \%$ de S, $0,05 \%$ de B, $0,08 \%$ de $\mathrm{Cu}, 0,15 \%$ de $\mathrm{Mn}$ e $0,3 \%$ de $\mathrm{Zn}$.

Foram avaliados seis híbridos de girassol. Cada parcela era composta por sete linhas, espaçadas de $0,75 \mathrm{~m}$, com $6,0 \mathrm{~m}$ de comprimento, totalizando $31,5 \mathrm{~m}^{2}$ por parcela e uma área experimental de $756 \mathrm{~m}^{2}$. A área útil utilizada foi composta pelas cinco linhas centrais com comprimento de $3,0 \mathrm{~m}$, resultando em $11,25 \mathrm{~m}^{2} \mathrm{de}$ área útil por parcela.

O delineamento experimental utilizado foi de blocos ao acaso com seis tratamentos, correspondentes a seis híbridos de girassol, com quatro repetições por tratamento. Os híbridos avaliados foram o H250, $\mathrm{H} 360 \mathrm{e} \mathrm{H} 358$ da empresa Helianthus, o híbrido Aguará 3 da Atlântica Sementes e os híbridos MG2 e M734 da Down Agrosciences.

Aos 17 dias após a emergência (DAE), foi realizado o raleio, deixando quatro plantas por metro, obtendo uma população de 53 mil plantas ha ${ }^{-1}$. Nessa mesma data foi realizada a adubação de cobertura, com $50 \mathrm{~kg} \mathrm{ha}^{-1}$ de $\mathrm{N}$, na forma de uréia.

Os valores de temperatura e pluviosidade durante o período do experimento são apresentados na Tabela 1 . Verifica-se que o total de pluviosidade atendeu as exigências da cultura (CASTRO; FARIAS, 2005).

No início do florescimento, foram realizadas as avaliações de altura de plantas (AP) e diâmetro de caule (DC). Essas medidas foram tomadas de cinco 
Tabela 1 - Valores de temperatura mínima, temperatura máxima, temperatura média e pluviosidade no período de fevereiro a junho de 2007. Palotina, 2007

\begin{tabular}{lcccccc}
\hline & fev & mar & abr & mai & jun & total \\
\hline T mín $\left({ }^{\circ} \mathrm{C}\right)$ & 19 & 15 & 12 & 3 & 3 & - \\
T máx $\left({ }^{\circ} \mathrm{C}\right)$ & 35 & 37 & 36 & 32 & 31 & - \\
T média $\left({ }^{\circ} \mathrm{C}\right)$ & 27 & 26 & 24 & 17,5 & 17 & - \\
Pluviosidade $(\mathrm{mm})$ & 181 & 188 & 193 & 114 & 3 & 728 \\
\hline
\end{tabular}

Fonte: C.Vale

plantas por parcela. Destas, duas foram coletadas e seccionadas para determinar as variáveis massa seca de folhas (MSF), massa seca de caule e pecíolos (MSCP), massa seca total (MST) e área foliar (AF).

A colheita foi realizada no dia 23 de junho de 2007, aos 108 dias após a emergência (DAE). Para tanto, foram colhidos três metros das cinco linhas centrais, retirando seus capítulos, com os quais se realizou as avaliações dos componentes de produção massa de grãos por capítulo (MGC), diâmetro de capítulo (DCAP), percentagem de grãos normais (GN), massa de mil grãos (MMG) e número de grãos por capítulo (NGC) e realizado o cálculo de produtividade (PROD). Foram determinados também os teores de óleo (TO) e de proteína bruta (PB). Com os dados de teor de óleo e produtividade foi calculado o rendimento de óleo $(\mathrm{RO})$.

Os dados foram submetidos à análise de variância pelo teste $\mathrm{F}(\mathrm{p}<0,05)$ e as médias dos tratamentos foram comparadas pelo teste de Tukey $(\mathrm{p}<0,05)$. Foram realizadas análise de correlação de Pearson $(n=24)$ entre componentes de produção, altura, produtividade, teor de óleo, teor de proteína bruta e rendimento de óleo e análise de regressão entre produtividade e os componentes de produção e entre teor de óleo e teor de proteína bruta.

\section{RESULTADOS E DISCUSSÃO}

Os resultados indicam efeitos não significativos da fonte de variação genótipo para a maioria das variáveis biométricas (Tabela 2). Apenas para a variável altura de plantas os dados foram significativos. Para esta variável, os maiores valores foram encontrados nos híbridos H358 e MG2, com 166 e $163 \mathrm{~cm}$, respectivamente. Ambos híbridos, M734 e Aguará 3 foram inferiores, com $149 \mathrm{~cm}$ de altura.

Oshíbridosapresentaramalturasreduzidasem relação a cultivos realizados no verão (EMPRESA BRASILEIRA DE PESQUISAAGROPECUÁRIA, 2009). Isso mostra que o plantio em safrinha confere às plantas alturas inferiores, sendo uma característica desejável, pois isso reduz o risco

Tabela 2 - Médias fenotípicas, teste F e de Tukey, coeficiente de variação e média geral das variáveis biométricas para seis híbridos de girassol. Palotina, 2007

\begin{tabular}{|c|c|c|c|c|c|c|}
\hline Híbrido & AP & $\mathrm{DC}$ & MSF & MSPC & MST & $\mathrm{AF}$ \\
\hline MG2 & $163 \mathrm{a}$ & 27,13 & 62,78 & 95,74 & 166,59 & 7051,2 \\
\hline M734 & $149 \mathrm{~b}$ & 26,72 & 52,08 & 82,96 & 139,36 & 6827,5 \\
\hline Aguará 3 & $149 \mathrm{~b}$ & 26,52 & 45,43 & 73,32 & 127,01 & 5865,0 \\
\hline $\mathrm{H} 250$ & $157 \mathrm{ab}$ & 26,63 & 51,33 & 85,58 & 148,67 & 6692,5 \\
\hline H360 & $162 \mathrm{ab}$ & 27,33 & 59,39 & 97,99 & 166,82 & 7156,2 \\
\hline H358 & $166 \mathrm{a}$ & 26,40 & 52,71 & 90,71 & 156,93 & 6631,2 \\
\hline QM & 0,01946 & 0,53027 & 615,06 & 1322,75 & 4036,24 & 33622,22 \\
\hline $\mathrm{F}$ & $3,106^{*}$ & $0,133^{\mathrm{ns}}$ & $1,294^{\mathrm{ns}}$ & $0,953^{\mathrm{ns}}$ & $1,113^{\mathrm{ns}}$ & $0,391^{\mathrm{ns}}$ \\
\hline $\mathrm{CV}$ & 3,09 & 7,46 & 20,21 & 21,23 & 19,95 & 21,85 \\
\hline
\end{tabular}

AP: altura de planta (cm). DC: diâmetro de caule (mm). MSF: massa de matéria seca de folhas $\left(\mathrm{g}\right.$ planta $\left.{ }^{-1}\right)$. MSPC: massa de matéria seca de caule + pecíolos $\left(\mathrm{g}\right.$ planta $\left.{ }^{-1}\right)$. MST: massa de matéria seca total $\left(\mathrm{g}\right.$ planta-1). AF: área foliar $\left(\mathrm{cm}^{2}\right)$. **, * : significativo a $1 \%$ e $5 \%$ pelo teste $\mathrm{F}$ respectivamente. Médias seguidas pela mesma letra, nas colunas, pertencem ao mesmo grupo pelo teste de Tukey a 5\% 
de acamamento. Em plantio realizado em outono, Heckler (2002) também encontrou alturas reduzidas para todos os genótipos. A altura é uma característica importante quando se trata de agricultura mecanizada, sendo que ela deve ser uniforme para proporcionar uma colheita mecanizada adequada, sem perdas na lavoura. Ivanoff et al. (2010) constataram problemas de desuniformidade para a variável altura, diâmetro de caule e diâmetro de capítulo na variedade Embrapa 122/V2000, sendo que essa desuniformidade pode limitar o uso da colheita mecanizada e do plantio em grandes áreas.

Para os componentes de produção, todas as variáveis apresentaram diferença significativa entre os híbridos (Tabela 3). Para massa de grãos por capítulo o maior valor foi encontrado no híbrido H360. Ele foi superior somente em relação aos híbridos Aguará 3 e H358. Em relação ao diâmetro de capítulo, os híbridos H360 e M734 foram superiores ao híbrido H358, Aguará 3 e H250. Na variável grau de enchimento, o híbrido M734 foi superior aos híbridos Aguará 3 e H250. Para massa de mil grãos, os híbridos MG2, M734 e H358 tiveram valores superiores aos híbridos Aguará 3, H250 e H360 e na variável número de grãos por capítulo os híbridos H360 e MG2 foram superiores ao híbrido H358.

Observa-se um comportamento semelhante dos componentes de produção em alguns híbridos. O híbrido H360 apresentou valores superiores para massa de grãos por capítulo, diâmetro de capítulo, grau de enchimento e número de grãos por capítulo e o híbrido MG2 apresentou valores superiores para todos os componentes de produção. Da mesma forma, o híbrido H250 obteve os menores valores para todos os componentes, com exceção da massa de grãos por capítulo (Tabela 3).

Essa relação pode ser observada na Tabela 4, onde os dados mostram correlação significativa entre os cinco componentes de produção. Com exceção da correlação entre NGC com GN e MMG, todas as outras correlações entre os cinco componentes de produção foram significativas. Desta forma o acréscimo em algum desses componentes acarretará em aumento nos outros.

Tabela 3 - Médias genotípicas, teste F e de Tukey, coeficiente de variação e média geral dos componentes da produção, teor de proteína e de óleo e rendimento de óleo para seis híbridos de girassol. Palotina, 2007

\begin{tabular}{lccccc}
\hline \multicolumn{1}{c}{ Híbrido } & MGC & DCAP & GN & MMG & NGC \\
\hline MG2 & $81,67 \mathrm{ab}$ & $16,22 \mathrm{ab}$ & $73,94 \mathrm{ab}$ & $57,36 \mathrm{a}$ & $1289 \mathrm{ab}$ \\
M734 & $74,00 \mathrm{abc}$ & $17,28 \mathrm{a}$ & $80,75 \mathrm{a}$ & $62,68 \mathrm{a}$ & $1109 \mathrm{bc}$ \\
Aguará 3 & $57,67 \mathrm{bc}$ & $14,57 \mathrm{bc}$ & $64,79 \mathrm{bc}$ & $48,68 \mathrm{~b}$ & $1147 \mathrm{bc}$ \\
H250 & $61,00 \mathrm{abc}$ & $14,92 \mathrm{bc}$ & $59,39 \mathrm{c}$ & $46,86 \mathrm{~b}$ & $1175 \mathrm{bc}$ \\
H360 & $83,67 \mathrm{a}$ & $17,60 \mathrm{a}$ & $74,55 \mathrm{ab}$ & $48,68 \mathrm{~b}$ & $1582 \mathrm{a}$ \\
H358 & $56,00 \mathrm{c}$ & $13,97 \mathrm{c}$ & $73,78 \mathrm{ab}$ & $58,21 \mathrm{a}$ & $918 \mathrm{c}$ \\
\hline QM & 462,656 & 8,948 & 237,620 & 174,103 & 195919,900 \\
F & $3,616^{*}$ & $10,824^{* *}$ & $7,629^{* *}$ & $12,589^{* *}$ & $8,584^{* *}$ \\
CV & 12,66 & 5,77 & 7,84 & 6,93 & 12,56 \\
\hline \multicolumn{1}{c}{ Híbrido } & PROD & PB & TO & RO & \\
\hline MG2 & $1766,75 \mathrm{a}$ & $13,88 \mathrm{a}$ & $42,65 \mathrm{a}$ & $754,31 \mathrm{ab}$ & \\
M734 & $1582,28 \mathrm{ab}$ & $15,47 \mathrm{a}$ & $35,05 \mathrm{c}$ & $553,62 \mathrm{ab}$ & \\
Aguará 3 & $1218,83 \mathrm{ab}$ & $15,34 \mathrm{a}$ & $38,81 \mathrm{~b}$ & $473,53 \mathrm{ab}$ & \\
H250 & $923,96 \mathrm{~b}$ & $14,69 \mathrm{a}$ & $43,31 \mathrm{a}$ & $399,59 \mathrm{~b}$ & \\
H360 & $1864,73 \mathrm{a}$ & $14,61 \mathrm{a}$ & $44,79 \mathrm{a}$ & $836,20 \mathrm{a}$ & \\
H358 & $1455,92 \mathrm{ab}$ & $14,87 \mathrm{a}$ & $44,17 \mathrm{a}$ & $645,89 \mathrm{ab}$ & \\
\hline QM & 566324,657 & 1,317 & 57,076 & 111519,271 & \\
F & $4,480^{*}$ & $0,732^{\text {ns }}$ & $61,611^{* *}$ & $9,490 * *$ & \\
CV & 24,21 & 9,06 & 2,85 & 21,75 & \\
\hline
\end{tabular}

MGC: massa de grãos por capítulo (g). DCAP: diâmetro de capítulo (cm). GN: percentagem de grãos normais (\%). MMG: massa de mil grãos (g). NGC: número de grãos por capítulo. PROD: produtividade $\left(\mathrm{kg} \mathrm{ha}^{-1}\right)$. PB: proteína bruta (\%). TO: teor de óleo (\%). RO: rendimento de óleo (kg ha-1). **, *, ns: significativo a $1 \%, 5 \%$ e não significativo pelo teste $\mathrm{F}$, respectivamente. Médias seguidas pela mesma letra, nas colunas, pertencem ao mesmo grupo pelo teste de Tukey a $5 \%$ 
Tabela 4 - Coeficiente de correlação (r) entre componentes de produção, produtividade, teor de óleo, teor de proteína bruta e rendimento de óleo. Palotina, 2007

\begin{tabular}{lccccccccc}
\hline & AP & MGC & DCAP & GN & MMG & NGC & PROD & PB & TO \\
\hline MGC & 0,16 & - & - & - & - & - & - & - & - \\
DCAP & $-0,01$ & $0,89^{* *}$ & - & - & - & - & - & - & - \\
GN & 0,16 & $0,72^{* *}$ & $0,71^{* *}$ & - & - & - & - & - & - \\
MMG & 0,07 & $0,48^{*}$ & $0,44^{*}$ & $0,84^{* *}$ & - & - & - & - & - \\
NGC & 0,17 & $0,80^{* *}$ & $0,71^{* *}$ & 0,257 & $-0,13$ & - & - & - & - \\
PROD & 0,08 & $0,62^{* *}$ & $0,47^{*}$ & $0,60^{* *}$ & $0,49 *$ & $0,47 *$ & - & - & - \\
PB & 0,16 & $-0,12$ & $-0,02$ & 0,08 & 0,06 & $-0,14$ & $-0,26$ & - & - \\
TO & $0,63^{* *}$ & 0,09 & $-0,13$ & $-0,18$ & $-0,33$ & 0,33 & 0,14 & $-0,34$ & - \\
RO & 0,26 & $0,58^{* *}$ & $0,42^{*}$ & $0,49^{*}$ & 0,35 & $0,56^{* *}$ & $0,96^{* *}$ & $-0,33$ & $0,41^{*}$ \\
\hline
\end{tabular}

AP: altura de planta (cm). MGC: massa de grãos por capítulo (g). DCAP: diâmetro de capítulo $(\mathrm{cm})$. GN: percentagem de grãos normais $(\%)$. MMG: massa de mil grãos (g). NGC: número de grãos por capítulo. PROD: produtividade $\left(\mathrm{kg} \mathrm{ha}^{-1}\right)$. PB: proteína bruta (\%). TO: teor de óleo (\%). RO: rendimento de óleo $\left(\mathrm{kg} \mathrm{ha}^{-1}\right)$.**, * significativo a 1 e $5 \%$, respectivamente. $\mathrm{n}=24$

A correlação significativa e positiva entre diâmetro de capítulo e massa de mil grãos ( $\mathrm{r}=$ $0,44 * *)$ foi constatada também por Khan (2001), Chikkadevaiah et al. (2002), Habib et al. (2007) e Machikowa e Saetang (2008). As variáveis número de grãos por capítulo e diâmetro de capítulo apresentaram correlação significativa e positiva $\left(\mathrm{r}=0,71^{* *}\right)$. Este comportamento foi encontrado em experimentos realizados por Habib et al. (2007), Hladni et al. (2006), Farhatullah et al. (2006) e Khan (2001).

A relação entre os componentes de produção e o comportamento similar destes para os híbridos acarretaram em uma resposta em produtividade. Desta forma os híbridos H360 e MG2 apresentaram produtividades superiores em relação ao híbrido $\mathrm{H} 250$ (Tabela 2).

A resposta da produtividade em função dos componentes de produção pode ser mais bem visualizada na Tabela 3 , onde MGC $(\mathrm{r}=0,62 * *), \operatorname{DCAP}(\mathrm{r}=0,47 *)$, GN $\left(r=0,60^{* *}\right)$ e MMG $(r=0,49 *)$ apresentaram correlação significativa e positiva. Esses dados corroboram os encontrados por Habib et al. (2007), Hladni et al. (2006) e Khan (2001), que encontraram a mesma resposta para os componentes massa de mil grãos, numero de grãos por capítulo e diâmetro de capítulo. Mijic et al. (2009) e Kaya et al. (2007) encontraram correlação positiva para massa de mil grãos. Machikowa e Saetang (2008) encontraram essa resposta para diâmetro de capítulo, massa de mil grãos e percentagem de grãos normais. Chikkadevaiah et al. (2002) encontraram correlação significativa e positiva para massa de mil grãos e diâmetro de capítulo.

Segundo Amorim e Souza (2005) os híbridos simples comerciais são germoplasmas prioritários para a extração de linhagens em um programa de melhoramento, já que foram extensivamente melhorados, tendo acumulados vários alelos desejáveis. Carvalho e Toledo (2008) obtiveram linhagens fêmeas a partir de híbridos comerciais, tendo a vantagem de explorar germoplasmas superiores (híbridos comerciais). Desta forma, a seleção de materiais que apresentem maiores valores de diâmetro de capítulo, massa de grãos por capítulo, percentagem de grãos normais e massa de mil grãos permitirá a obtenção de materiais com boa produtividade.

Na Tabela 5 estão dispostos os resultados da análise de regressão da produtividade em função dos componentes de produção e entre teor de óleo e teor de proteína. Pode-se observar significância para todas as regressões, com exceção de PROD X NGC, sendo que para PROD X DCAP e TO X PB a resposta foi linear.

A massa de grãos por capítulo (Figura 1) apresenta o ponto de máxima contribuição na produtividade com $78,2 \mathrm{~g}$, correspondendo a uma produtividade de 1.872 $\mathrm{kg} \mathrm{ha}^{-1}$. Para percentagem de grãos normais o ponto de máxima é de 79,9\%, resultando em uma produtividade de $1.821 \mathrm{~kg} \mathrm{ha}^{-1}$ (Figura 2). Para a interação diâmetro de capítulo e produtividade houve resposta linear positiva (Figura 3). Kaya et al. (2007) encontraram resposta significativa e quadrática entre produtividade e massa de mil grãos, com decréscimo da relação positiva próximo a $70 \mathrm{~g}$. Esse comportamento ocorreu com 59,7 g, refletindo uma produtividade de $1.796 \mathrm{~kg} \mathrm{ha}^{-1}$ (Figura 4), sendo que após esse limite a produtividade é prejudicada.

Quanto ao teor de óleo, observamos que os híbridos Aguará 3 e M734 foram inferiores aos demais (Tabela 3). Essa variável apresentou correlação apenas com altura de plantas, sendo esta positiva e significativa (Tabela 4). Esse resultado corrobora encontrados por Farhatullah 
et al. (2006), Khan (2001), Mijic et al. (2009) e Kaya et al. (2007). Para proteína bruta não houve diferença significativa entre os híbridos (Tabela 3). Apesar disso, a análise de regressão mostra comportamento linear negativo entre essas variáveis (Tabela 5), sendo que esse comportamento é mais bem observado na Figura 5.

Tabela 5 - Quadro de ANAVA da análise de regressão entre produtividade e componentes de produção e entre teor de óleo e teor de proteína

\begin{tabular}{lccc}
\hline & $\mathrm{R}^{2}$ & $\mathrm{~F}$ & $\mathrm{QM}$ \\
\hline PROD X MGC & 0,4969 & $10,37^{* *}$ & 1229832,5 \\
PROD X GN & 0,4677 & $9,23 * *$ & 1157669,6 \\
PROD X MMG & 0,3332 & $5,25 *$ & 824810,3 \\
PROD X DCAP & 0,2018 & $16,20^{*}$ & 957099,4 \\
PROD X NGC & 0,1539 & $4,485 \mathrm{~ns}$ & 751995,8 \\
TO X PB & 0,0986 & $10,80^{*}$ & 29,17 \\
\hline
\end{tabular}

MGC: massa de grãos por capítulo (g). DCAP: diâmetro de capítulo (cm). GN: percentagem de grãos normais (\%). MMG: massa de mil grãos (g). NGC: número de grãos por capítulo. PROD: produtividade $\left(\mathrm{kg} \mathrm{ha}^{-1}\right)$. PB: proteína bruta (\%). TO: teor de óleo (\%).**, *, ns: significativo a $1 \%, 5 \%$ e não significativo pelo teste $\mathrm{F}$, respectivamente

Figura 1 - Relação entre massa de grãos por capítulo e produtividade. Palotina, 2007

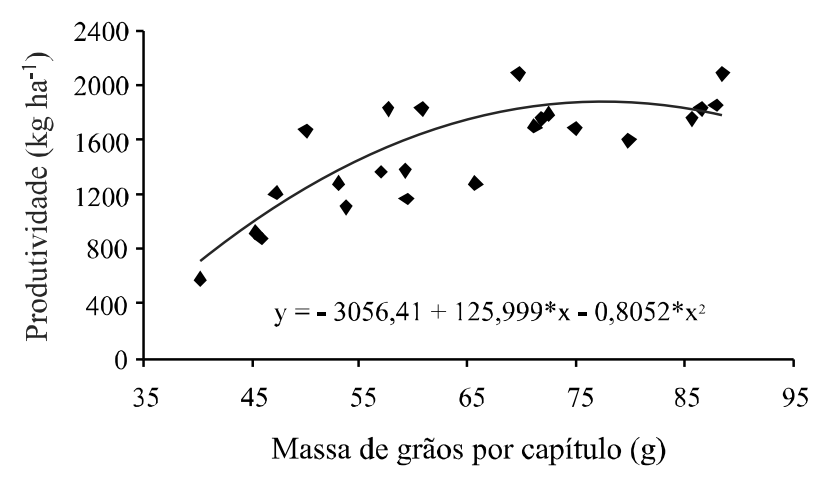

Figura 2 - Relação entre percentagem de grãos normais e produtividade. Palotina, 2007

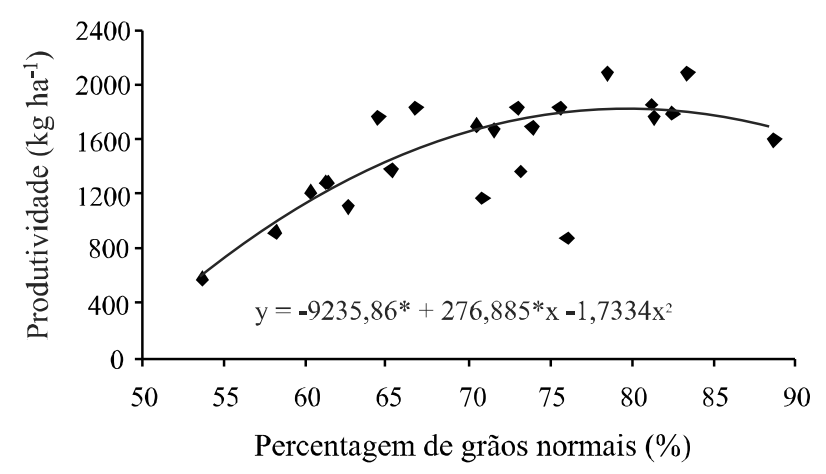

Figura 3 - Relação entre diâmetro de capítulo e produtividade. Palotina, 2007

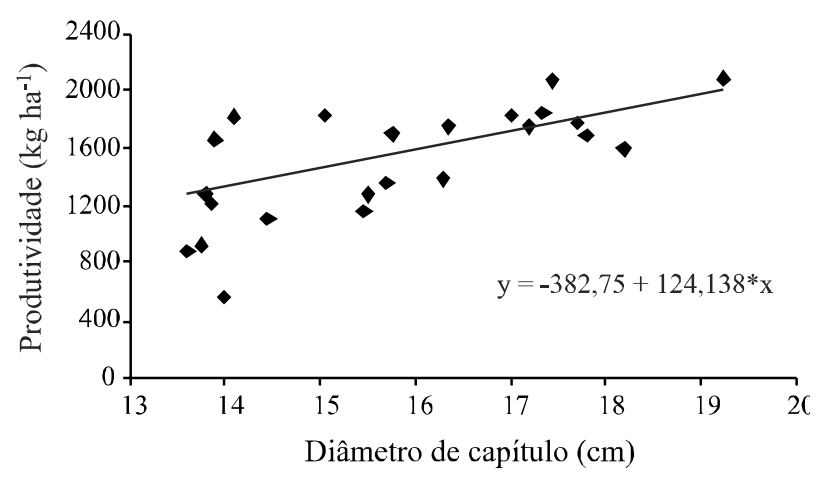

Figura 4 - Relação entre massa de mil grãos e produtividade. Palotina, 2007

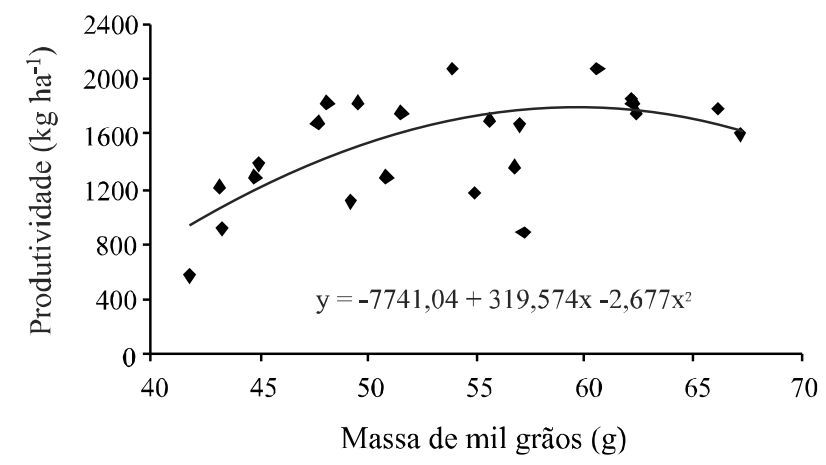

Figura 5 - Relação entre teor de óleo em função do teor de proteína. Palotina, 2007

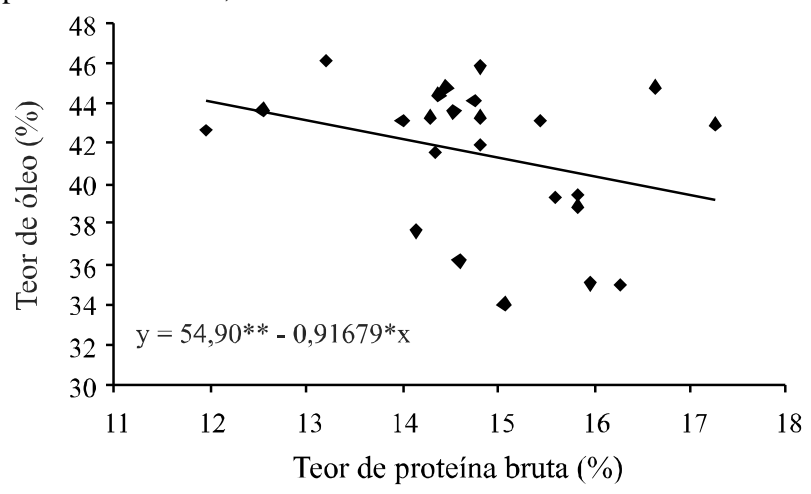

Segundo Marcos Filho (2005), há relação inversa entre os teores de proteínas e de óleo, ou seja, a elevação do teor de óleo ocorre paralelamente à redução do de proteínas e vice-versa, justificando o comportamento linear negativo. A partir dessa afirmação podemos analisar melhor o comportamento dos híbridos observando a Figura 6 , onde estes estão agrupados de acordo com a resposta de teor de óleo e proteína. 
Figura 6 - Relação entre teor de óleo e proteína bruta para cada híbrido de girassol. Palotina, 2007

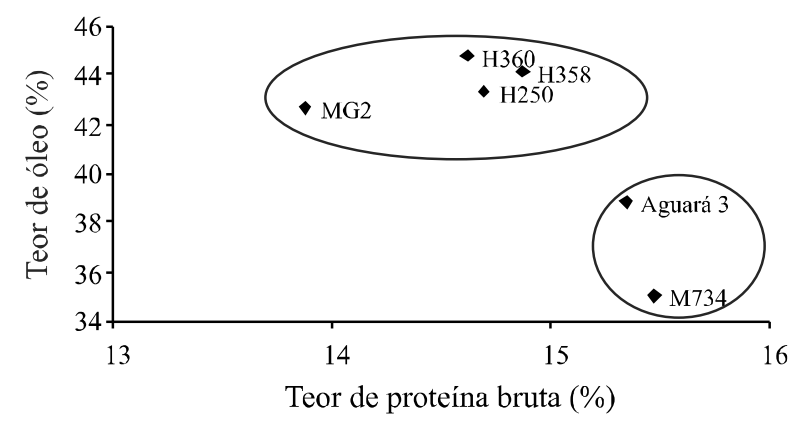

Quatro híbridos podem ser agrupados apresentando os maiores valores de teor de óleo (MG2, H360, H358 e H250) e menores valores de proteína bruta. Os dois híbridos com menor teor de óleo (Aguará 3 e M734) se agrupam com maior proteína bruta.

O agrupamento dos híbridos provavelmente é definido acerca do direcionamento do híbrido durante o programa de melhoramento de cada empresa. Sabe-se, por exemplo, que o híbrido M734 é recomendado para a produção de silagem e produção de grãos, enquanto que o híbrido MG2 é destinado à produção de grãos. Segundo Mello et al. (2006a), o híbrido M734 apresentou melhor relação entre fenologia, produtividade e composição bromatológica, obtendo assim silagem de elevada qualidade. O híbrido M734 também apresentou-se dentre as melhores relações entre análise química, digestibilidade, nutrientes digestíveis toais (NDT) e cinética de degradação ruminal (MELLO et al., 2006b).

Para a variável rendimento de óleo somente o híbrido H360 foi superior ao H250 (Tabela 3). Essa variável apresentou comportamento semelhante à variável produtividade na análise de correlação, sendo que para rendimento de óleo a exceção foi da variável MMG (Tabela 4). Mijic et al. (2009) encontraram o mesmo comportamento para massa de mil grãos, produtividade e teor de óleo. Chikkadevaiah et al. (2002) encontraram a mesma resposta para massa de mil grãos, diâmetro de capítulo, produtividade e teor de óleo.

\section{CONCLUSÕES}

1. Os híbridos H360 e MG2 estão dentre os híbridos mais produtivos e os que possuem maior teor de óleo na região de estudo, obtendo assim maior rendimento de óleo, sendo recomendados para produção de óleo;

2. Os híbridos M734 e Aguará 3 obtiveram boas produtividades e menores teores de óleo e maiores teores de proteína bruta na região de estudo, sendo assim, direcionados para alimentação animal;

3. A seleção de materiais a partir dos componentes de produção diâmetro de capítulo, massa de grãos por capítulo, percentagem de grãos normais e massa de mil grãos ocasionará a seleção de materiais promissores em produtividade para a região de estudo, baseados nas correlações significativas entre os componentes de produção e produtividade.

\section{REFERÊNCIAS}

AMORIM, E. P.; SOUZA J. C. Híbridos de milho inter e intrapopulacionais obtidos a partir de populações $S_{0}$ de híbridos simples comerciais. Bragantia, v. 64, n. 03, p. 561567, 2005.

CARVALHO, C. G. P.; TOLEDO, J. F. F. Extracting female inbred lines from commercial sunflower hybrids. Pesquisa Agropecuária Brasileira, v. 43, n. 09, p. 1159-1162, 2008.

CASTIGLIONI, V. B. R.; OLIVEIRA, M. F. Melhoramento do Girassol. In: BORÉM, Aluízio. Melhoramento de espécies cultivadas. 2. Ed. Viçosa: UFV, 1999. cap. 10, p. 351-384.

CASTRO, C.; FARIAS, J. R. B. Ecofisiologia do girassol. In: LEITE, R. M. V. B.; BRIGHENTI, A. M.; CASTRO, C. Girassol no Brasil. Londrina: Embrapa Soja, 2005. cap. 9, p.163-218.

CHIKKADEVAIAH, H.; SUJATHA, H. L.; NANDINI, C. Correlation and path analysis in sunflower. Helia, v. 25, n. 37 , p. 109-118, 2002.

COMPANHIA NACIONAL DE ABASTECIMENTO. Acompanhamento da safra brasileira: Grãos. Décimo Segundo Levantamento. Disponível em: <http:// www.conab.gov.br/OlalaCMS/uploads/arquivos/ 7e05515f8222082610088f5a2376c6af.pdf >. Acesso em: 30 set. 2010 .

EMPRESA BRASILEIRA DE PESQUISA AGROPECUÁRIA. Informes da avaliação de genótipos de girassol 2007/2008 e 2008. Londrina: Embrapa Soja, 2009. 107 p. (Documentos, 316).

FARHATULLAH, FAROOQ-E-AZAM; KHALIL, I. H. Path analysis of the coefficients of sunflower (Helianthus annuus L.) hybrids. International Journal of Agriculture e Biology, v. 8, n. 5, p. 621-625, 2006.

HABIB, H. et al. Correlation and path analysis for seed yield in sunflower (Helianthus annuus L.) under charcoal rot (Macrophomina phaseolina) stress conditions. International Journal of Agriculture e Biology, v. 09, n. 02, p. 362-364, 2007.

HECKLER, J. C. Sorgo e girassol no outono-inverno, em sistema plantio direto, no Mato Grosso do Sul, Brasil. Ciência Rural, v. 32, n. 03, p. 517-520, 2002.

HLADNI, N. et al. Combining ability for oil content and its correlations with other yield components in sunflower (Helianthus annuus L.). Helia, v. 29, n. 44, p. 101-110, 2006. 
IVANOFF, M. E. A. et al. Formas de aplicação de nitrogênio em três cultivares de girassol na savana de Roraima. Revista Ciência Agronômica, v. 41, n. 03, p. 319-325, 2010.

KAYA, Y. et al. Determining the relationships between yield and yield attributes in sunflower. Turkish Journal of Agriculture and Forestry, v. 1, n. 31, p. 237-244, 2007.

KHAN,A. Yield performance, heritability and interrelationship in some quantitative traits in sunflower. Helia, v. 24, n. 34, p. 35-40, 2001.

LAZZAROTTO, J. J.; ROESSING, A. C.; MELlO, H. C. O agronegócio do girassol no mundo e no Brasil. In: LEITE, R. M. V. B.; BRIGHENTI, A. M.; CASTRO, C. Girassol no Brasil. Londrina: Embrapa Soja, 2005. cap. 2, p. 15-42.

MACHIKOWA, T.; SAETANG, C. Correlation and path coefficient analysis on seed yield in sunflower. Suranaree Journal of Science and Technology, v. 15, n. 03, p. 243248, 2008.

MARCOS FILHO, J. Fisiologia de sementes de plantas cultivadas. Piracicaba: Fealq, 2005. 495 p.
MELLO, R. et al. Características fenológicas, produtivas e qualitativas de híbridos de girassol em diferentes épocas de semeadura para produção de silagem. Revista Brasileira de Zootecnia, v. 35, n. 03, p. 672-682, 2006a.

MELLO, R. et al. Composição química, digestibilidade e cinética de degradação ruminal das silagens de híbridos de girassol em diferentes épocas de semeadura. Revista Brasileira de Zootecnia, v. 35, n. 04, p. 1523-1534, 2006 b.

MIJIC, A. et al. Quantitative analysis of oil yield and its components in sunflower (Helianthus annuus L.). Romanian Agricultural Research, v. 01, n. 26, p. 41-46, 2009.

OLIVEIRA, M. F.; CASTIGLIONI, V. B. R.; CARVALHO, C. G. P. Melhoramento do girassol. In: LEITE, R. M. V. B.; BRIGHENTI, A. M.; CASTRO, C. Girassol no Brasil. Londrina: Embrapa Soja, 2005. cap. 11, p. 269-297.

PAES, J. M. V. Utilização do girassol em sistema de cultivo. Informe Agropecuário, v. 26, n. 229, p. 34-41, 2005.

PORTO, W. S.; CARVALHO, C. G. P.; PINTO, R. J. B. Adaptabilidade e estabilidade como critérios para seleção de genótipos de girassol. Pesquisa Agropecuária Brasileira, v. 42, n. 04, p. 491-499, 2007. 